\title{
Antineoplastons Therapy
}

National Cancer Institute

\section{Source}

National Cancer Institute. Antineoplastons Therapy. NCI Thesaurus. Code C67027.

A complimentary/alternative cancer therapy that uses antineoplastons to protect the body from disease. 